\title{
When the Journalist Meets New Media: Some Reflections on the Interactions between Journalist and New Media Driven Journalism in Turkey
}

\author{
Assoc. prof. Serhat KAYMAS, PhD \\ Higher Vocational School \\ Hacettepe Unıversity, Turkey \\ E-mail: ahmetserhat.kaymas@windowslive.com
}

\begin{abstract}
This study aims to answer the following questions: How do journalists in Turkey discuss the emergence of new media specific technological forms? and In which circumstances are new media forms seen as contributing to the practices of journalism and when are they threatening it? Each mode in the study points to the relationship between journalism and technology and carries different implications regarding the changing nature of journalism in the digital age. The study is based on 22 in-depth interviews with online journalists and a survey based on "Likert attitude analysis" (N=126). In the study, journalists are selected from traditional and online news agencies, and the groups are consistent in terms of age, gender, and professional experiences. The findings of the study indicate that online journalism is required for diversity in the free market of the media sector, especially in Turkey.
\end{abstract}

Keywords: Journalism; Internet; New media; Ownership concentration; Pluralisation. 


\section{Introduction}

This article deals with the interactions between journalism and new media ecology and in this sense, changing occupational perceptions of journalists' through with a survey and semi-structured deep interviews. When neoliberal policies came into effect after the 1990s, the new era implied radical changes for the media sector and its integrated markets. At the global level, ongoing transformations included concentration of ownership, monopolization, insufficient media policies, mismanagement of new media by government policy, ineffective national media policies in the age of neoliberalism, and firm restrictions on freedom of information and expression. Perhaps the most important transition is experienced by journalism and in journalistic routines. As Jenifer Alejandro (2010, p. 9) mentions; "in the old days, a reporter was given a lead or went out to find a story. Today, many stories are received third hand (sometimes even fourth or fifth hand) through Facebook posts or Tweets or Digg so that by the time a story is assigned to the reporter, the story in some form or another is already out there in the social media universe". In this sense, the most important transition process is often seen to be the migration of the journalist and journalistic routines into new media and new media-driven journalism, changes are not restricted only to this area. In fact, this migration into the new media world has also been affected by the nature and meaning of the news in at least three important aspects (Deuze 1999, p. 373). These aspects are: (1) the chancing media ecology and its impact on the journalism profession and media outlets. This process is also called a "migration" from traditional media environment to the new media ecology. (2) the changing nature of journalist's perception of his/her profession and in this sense raised an important question with regarding changing occupational practices, for instance "who is a journalist?" (3) the changing nature on news making practices and in this sense, new media and communication technologies effect on these process. As Gillian Doyle (2016, p. 36) has points out; "digital convergence and growth of the internet have altered the landscape of media and cultural provision irrevocably in recent years, blurring sectoral and geographic boundaries, changing audience consumption behavior, altering and overturning conventional conceptions of the supply chain, and transforming levels of revenue and resourcing across the media industry". But, among in these (ongoing) transformations journalism is the most exposed realm of media and cultural provisions at least two important aspects. These are (1) regarding with the growing technology's impact on the professionalism of journalistic routines such as the changing boundaries of the news reporting, transforming professionalism and in this sense emerging "new" journalism as a result of growing new media and information technologies. The other aspect is related directly with journalist' perception on his/her profession.

Regarding the Internet's potential contribution to democracy, Mark Deuze (1999, p. 373) claims that the Internet has the potential to make the journalist's role 
as an essential intermediary force in democracy "more or less superfluous." This optimistic view is often based on the Internet's technological capability, which offers the journalist a vast array of resources and endless technological possibilities. Additionally, journalist interaction with new media, particularly Facebook and Twitter, and with other social media practices, is seen as an important connection to other sources of information and news. Similarly, as Susan Currie Sivek (2010, p. 158) points out, social media represent an opportunity for journalists and their organizations to connect with the audience in critical new ways, particularly to reunite alienated readers and viewers with content and content creators largely distanced in the past. Another important contribution for the analysis of the interaction between new media and journalist stems from the Internet's technological properties.

The second dimension featured by the new information and communication technologies is called convergence. According to Sivek (2010, p. 159), convergence implies a new age of journalism. This is because, as Sivek (2010, p. 159) mentioned, "the journalists who strive to adopt convergent and multimedia approaches to news are already to being supplemented and will eventually be replaced by a new generation of journalists for whom convergence is the way things have always been." Since today's media industries are not shaped by the division of technologically distinct silos, they are increasingly characterized by a convergent, fluid, and independent "media ecosystem" (Deuze 2007, p. 6). Modern journalists are part of a technologically-driven system or are governed by the logic of technology and the new media ecosystem. The internet created its own version of journalism and journalistic routines, called digital or online journalism. This new version is characterized by three dimensions: (1) interactivity, (2) convergence, and finally (3) personalization (Deuze 1999, p. 377). As Weiss and Joyce (2009, p. 587) note, "the internet as a technological promise and a communication tool can be considered the place for McLuhan's Global Village, where traditional ideas of time and space are reconsidered."

In this study, Turkey's experience is evaluated under the abovementioned aspects. The research questions of this study are the following: (1) How do journalists in Turkey discuss the emergence of these specific technological forms? and (2) When are new work forms seen as contributing to the practices of journalism, and when as threatening it? This study discusses each research question within the wider context of the interaction between traditional- and new media-driven journalism, and especially personal experiences of the journalists deriving from traditional and new media ecology. The differences between traditional and new ecology is not only dealing with differences of the changing media environment, but also, perhaps the most important aspects are the perceptions on the occupation and occupational practices. As Ansgard Heinrich (2012, p. 61) pointed out, "I $t$ ]he journalism of the twentieth century can be characterized as an authority's commu- 
nication environment. The idea of trained professionals tied together as a group through organizational, professional or cultural status helped the journalistic profession to not only stabilize a group identity (Zelizer 2009), but also clearly defined the boundaries between who counted as a journalist and who did not." Therefore, new media ecology has inevitably paved the way for rethinking new norms, values, and routines for journalism. According to Agarwal and Barthel (2015, pp. 377-380), these differences can be classified into six categories: (a) organizational differences, (b) relational differences, (c) newsworthiness and perception of news differences, (d) online journalism's transparency against traditional journalism, (e) the differences of professional routines, and (f) professional practices, and in this sense, differences in the journalists' role identity perceptions. Therefore, online and traditional journalism have also produced a different set of professional norms. In this article, these ongoing differences are being evaluated by the "continuity and discontinuity" aspects of the new media ecology. On the other hand, the study is focused on the media ownership and conglomeration patterns in Turkey and market penetration rates, and in this sense, the study is mapped online journalism in Turkey and inquiry on the online journalists' identity and role perception in the new media ecology, by means of in-depth interviews.

\section{An Overview of the Turkey's New Media and Information \\ Technologies Infrastructure and New Media Markets}

With more than 30 million users and relatively high penetration rates, Turkey's new media infrastructure appears promising for future online journalism and journalistic outlets. However, the real condition of the media market is far from this hopeful picture. Turkey's new media infrastructure, like almost all those of its Western liberal counterparts, is plagued by monopolization and concentration of ownership. Therefore, the question of whether online journalism is possible in the age of media conglomerates is an important starting point for understanding online journalism and future generations of journalists. Turkey's new media infrastructure, users, and penetration rates are shown in Table 1.

Table 1. Turkey's new media infrastructure, users, and penetration rates

\begin{tabular}{ccccc}
\hline Country & Population & Internet Users & Penetration Rates (\%) & Rank in the Europe (\%) \\
\hline Turkey & $79,749,461$ & $36,455,000$ & 45.7 & 7.0 \\
\hline
\end{tabular}

Source: www.internetworldstats.com, 2016.

In terms of overall internet usage in Europe, Turkey is moderate, but possesses potential for expansion. According to recent statistics by Internet World Stats that list the top 10 internet-using countries in Europe, as of 2017, Turkey ranks fifth, among European Union member and candidate countries. 
Table 2. Top 20 Internet Countries with the Highest Number of Internet Users in 2017

\begin{tabular}{lrrr}
\hline \multicolumn{1}{c}{ Country or Region } & $\begin{array}{c}\text { Populations in 2017 } \\
\text { (estimated) }\end{array}$ & $\begin{array}{c}\text { Internet Users } \\
\text { (30 June 2017) }\end{array}$ & Internet Penetration Rates \\
\hline China & $1,388,232,693$ & $738,539,792$ & $53.2 \%$ \\
India & $1,342,512,706$ & $462,124,989$ & $34.4 \%$ \\
United States & $326,474,013$ & $286,94,362$ & $87.9 \%$ \\
Brazil & $211,243,220$ & $139,111,185$ & $65.9 \%$ \\
\hline Indonesia & $263,510,146$ & $13,700,000$ & $50.4 \%$ \\
Japan & $126,045,211$ & $118,453,595$ & $94.0 \%$ \\
Russia & $143,375,006$ & $109,552,842$ & $76.4 \%$ \\
Nigeria & $191,835,936$ & $91,598,757$ & $47.7 \%$ \\
Mexico & $130,222,815$ & $85,000,000$ & $65.3 \%$ \\
Bangladesh & $164,827,118$ & $73,347,000$ & $44.5 \%$ \\
Germany & $80,636,124$ & $72,290,285$ & $89.6 \%$ \\
Vietnam & $95,414,640$ & $64,000,000$ & $67.1 \%$ \\
United Kingdom & $65,511,098$ & $62,091,419$ & $94.8 \%$ \\
Philippines & $103,796,832$ & $57,607,242$ & $55.5 \%$ \\
Thailand & $68,297,547$ & $57,000,000$ & $83.5 \%$ \\
Iran & $80,945,526$ & $56,000,000$ & $70.0 \%$ \\
France & $64,938,716$ & $56,367,330$ & $86.8 \%$ \\
Turkey & $80,417,526$ & $56,000,000$ & $69.6 \%$ \\
Italy & $59,797,978$ & $51,836,798$ & $86.7 \%$ \\
Korea, South & $50,704,971$ & $47,013,649$ & $92.7 \%$ \\
\hline
\end{tabular}

Source: www.internetworldstats, 2017

With regard to the internet users and penetration rates, internet usage practices are not stable and constant. Conversely, as the internet technical capabilities and infrastructures keep developing, internet users and, of course, penetration rates are expanded. For instance, Turkey's internet users have been rising, ranging from 33.779.438 to 46.196 .720 since 2012, as shown in Table 3.

Table 3. Internet Users' and Penetrations' Channing Patterns in Turkey between the years 2012 and 2017

\begin{tabular}{cccccccc}
\hline Year & Internet Users & $\begin{array}{c}\text { Penetration } \\
\text { (\% of population) }\end{array}$ & $\begin{array}{c}\text { Total } \\
\text { Population }\end{array}$ & $\begin{array}{c}\text { Non-Users } \\
\text { (internetless) }\end{array}$ & $\begin{array}{c}\text { One Year } \\
\text { User } \\
\text { Change }\end{array}$ & $\begin{array}{c}\text { One Year } \\
\text { User Change }\end{array}$ & $\begin{array}{c}\text { Population } \\
\text { Change }\end{array}$ \\
\hline 2017 & $56,000,000$ & $69.6 \%$ & $80,417,526$ & $24,417,526$ & $11.2 \%$ & $9,803,280$ & $1.22 \%$ \\
2016 & $46,196,720$ & $58.0 \%$ & $79,622,062$ & $33,425,342$ & $5.1 \%$ & $2,242,750$ & $1.22 \%$ \\
2015 & $43,953,971$ & $55.9 \%$ & $78,665,830$ & $34,711,859$ & $11.1 \%$ & $4,385,829$ & $1.47 \%$ \\
2014 & $39,568,141$ & $51.0 \%$ & $77,523,788$ & $37,955,647$ & $12.2 \%$ & $4,314,708$ & $1.71 \%$ \\
2013 & $35,253,433$ & $46.3 \%$ & $76,223,639$ & $40,970,206$ & $4.4 \%$ & $1,473,995$ & $1.84 \%$ \\
\hline 2012 & $33,779,438$ & $45.1 \%$ & $74,849,187$ & $41,069,749$ & $6.7 \%$ & $2,118,819$ & $1.81 \%$ \\
\hline
\end{tabular}

Source: www.internetlivestats.com, 2017.

According to the Internet World Stats latest report (2017), internet has been gradually risen in the World Regions since 2012, despite the fact that the digital divide and inequalities of internet access still represent an important problem, es- 
pecially for the democratic communication possibilities. In Table 4, internet world growth is shown from 2000 to the March 2017.

Table 4. Internet World Growth between the years 2000 and 2017

\begin{tabular}{lrrr}
\hline \multicolumn{1}{c}{ World Regions } & $\begin{array}{c}\text { Internet Users } \\
\text { (Year: 2000) }\end{array}$ & $\begin{array}{c}\text { Internet Users } \\
\text { (Year: 2017) }\end{array}$ & $\begin{array}{c}\text { Growth (\%) } \\
\text { (Years: Between } \\
\text { 2000 and 2017) }\end{array}$ \\
\hline Asia & $114,304,000$ & $1,873,856,654$ & $1,539.4 \%$ \\
Europe & $105,096,093$ & $636,971,824$ & $506.1 \%$ \\
\hline Africa & $4,514,000$ & $345,676,501$ & $7,557.2 \%$ \\
\hline North America & $108,096,800$ & $320,068,243$ & $196.1 \%$ \\
\hline South America & $14,292,100$ & $277,294,854$ & $1,840.2 \%$ \\
\hline Middle East & $3,284,800$ & $141,931,765$ & $4,220.9 \%$ \\
Central America & $3,217,400$ & $90,116,568$ & $2,700.9 \%$ \\
Oceania / Australia & $7,620,480$ & $27,549,054$ & $261.5 \%$ \\
\hline The Caribbean & 559,419 & $18,507,960$ & $3,208.4 \%$ \\
World Total & $360,958,492$ & $3,731,973,423$ & $933.8 \%$ \\
\hline
\end{tabular}

Source: www.internetworldstats.com, 2017.

According to the latest report dealing with the internet's users' and penetration rates growth in the world regions, the numbers have steadily risen between 2000 and 2017. Although this hopeful scenery is apparently providing an opportunity to democratic communication possibilities and to the knowledge society, the real conditions of the media, especially new media and communication sector, are far away for this hope. For instance, Turkey ranks fifth and possesses potential for expansion of new media markets like almost all Western liberal countries, but given the reality of the She's media markets, the new media and communication subsector is plagued by commercialized media markets experiences and intensified ownership concentration. Table 5 shows some samples of online journals and news sites in Turkey. Although some are examples of independent news media outlets, they are inadequate for the whole media scene, and Turkey's media sector is mainly dominated by a few media conglomerates.

Table 5. Media conglomerates in Turkey (Adapted from https://m.bianet.org. 2017)

\begin{tabular}{ccc}
\hline Media Groups & Internet Companies & Portal \\
\hline Doğan & Doğan Online & www.e-kolay.net \\
Çukurova & Superonline & www.superonline.com \\
\hline Turkuaz & Turkport & www.turkport.com \\
\hline Sancak & Webbee & www.webbee.com \\
Doğuş & İxir & www.ixir.com \\
İhlas & Ihlas-net & www.ihlas.net \\
\hline
\end{tabular}


Only six players have dominated internet-wise notable internet service providers. This inequality is continued in the broadband internet penetration and, of course, internet subscribers in Turkey. Apart from ongoing digital inequalities and digital divides, the domination of a few media moguls on the entire media sector is high. In this sense, the relations between state and media owners call for a rethinking of political parallelism in the age of neoliberalism. Daniel Hallin and Paolo Mancini (2004, p. 2) identified four core dimensions to assess the comparative media systems analysis.

These interrelated dimensions for the comparative media analysis units are: (1) the structure of media markets: some aspects of the media market development, like newspaper circulation rates, newspaper and readership relationship, gender differences in newspaper reach, relative importance of newspapers and television as source of news, ratio of local, regional and national newspapers, degree of clear separation between sensational mass press and quality press, regional or linguistic segmentation of media markets, influence of bordering countries on the national media system. As Ali Çarkoğlu and Gözde Yavuz (2010, p. 616) mentioned, "in addition to ownership structure and allegiances between media and political elite, political tendencies are also discernable in media content more in some countries than others." Especially in Turkey, these ongoing tendencies, as "press politics parallelism," have generated highly relevant debates since Justice and Development Parties came to power in the 2002 general election, after Turkey's economy faced two economic crises, in November 2000 and February 2001. As Çarkoğlu and Yavuz (2010, p. 617) have pointed out, "the AKP's coming to power in the aftermath of the 2002 general election with about 34 percent of the popular vote capturing nearly two thirds of the seats in the Turkish Grand National Assembly, ignited those debates on the decline in media independence and emerged of an advocate / partisan (yandaş) media." In Turkey's experience, media and state relations must be re-evaluated under the shadow of the two economy political crises. During the economic crises, in November 2000 and February 2001, some of these media conglomerates, that were direct shareholder of the banks, were being taken over by the SDIF (Savings Deposit Insurance Funds). As Ali Çarkoğlu and Gözde Yavuz (2010, p.615) have pointed out that different newspapers in the Turkish media market appear to different degrees of concentration across the political parties amongst their readership communities. Therefore, political polarization and political tensions are partly continuing in the media outlets, irrespective of traditional newspaper or new media news portal. (2) Political parallelism refers to the actual role of the media, with respect to the quality of democratic public life. According to Antonio Ciaglia (2013, p. 543), political parallelism describes a situation of closeness between media and the political sys- 
tem, and between the types of logic on which these systems are based. Hallin and Mancini (2004, pp. 26-33) have established five indicators to assess the extent of political parallelism. These are, the extend of political orientation within media content, organizational connections between media and political organization, the tendency of media personal to take part in political life, partisanships of media audiences, journalists' role orientation and practices, the mode of pluralisation. As Raşit Kaya and Barış Çakmur (2010, p. 528) have pointed out, "in fact journalism in Turkey, where a formal protection of editorial autonomy has never existed, has to a significant extent not been an autonomous institution, but has been ruled by external forces, principally from the worlds of politics and of business." On the other hand, violence against journalists has escalated in recent years. Therefore, Freedom House's latest report, in 2016, has evaluated Turkey as "not free" in press freedom status and "partly free" in net freedom status (www.freedomhouse.org). Hallin and Mancini (2004, p. 53) addressed two main forms of pluralism. While individualized pluralism refers to covering different opinions and perspectives within one medium, organized pluralism addresses covering different opinions and perspectives within one media branch, and in this sense, differentiation of the media ownership. As Hallin and Mancini (2004, p. 53) have pointed out; "organized pluralist systems are characterized by strongly institutionalized social groups representing different segments of the population, which often play a central role in mediating their members' relations with the wider society and may be formally integrated into the process of making public policy".

The other aspect of political parallelism addresses the role, organization, and financial substitution of the public service broadcasting prior to globalization; with the advent of new media practices, media policies and political parallelism are identified within the borders of nation state, yet with the beginning of these two interrelated process, the researchers have got some challenging aspects of the media policies and political parallelism. In Hallin and Mancini's (2004, p. 110) study for comparative media systems analysis, the other aspect is (3) the professionalization of journalism. This aspect refers to the journalistic norms, values, and standards for journalism. This aspect is made up of three elements, such as editorial independence, journalists' autonomy from established powers whether media ownership or other pressure groups, development of distinct professional norms and values, and, finally, public service orientation of the journalist. But as Sheetal D. Agarwal and Michael L. Barthel (2015, p. 379) have mentioned, "the shift to online journalism has produced a corresponding tension and boundary struggles concerning who is or is not a journalist." In this respect, there already are two different approaches. In the first approach, some scholars, such as Deleuze and Sousa (in Agarwal and Barthel 2015, p. 379), have pointed out new media driven 
journalism and new media ecology have fundamentally altered the nature and meaning of journalism as a profession. In this context, new journalism practices such as citizen journalism have emerged; participatory culture has challenged the rationale for professional content over creation, filtering, and distribution of news as evidence for this ongoing transformation. Another perspective deals especially with technological properties of new media and changing journalism dialectics. According to this perspective (Agarwal and Barthel 2015, p. 379), ongoing technological changes have facilitated some opportunities for new media driven journalism, such as lowering the barriers for entry into the profession, diversification of media ownership, and journalists' self-definition on the profession of journalism. But as Agarwal and Barthel (2015, p. 379) pointed out, this perspective is "a new but a robust understanding of what a journalist is." The other perspective poses that traditional and new journalism are significantly different categories, and they are different professional self-understandings, so that they remain largely separate professional realms. In this sense, with the advent of new communication and information technologies, as Amy Schmitz Weiss (2014, p. 74) mentioned, "today's global media climate is undergoing a major transformation about how the media business operates and functions." Therefore, in the global media ecology, media policy makers faced new problems and they have to adjust to new regulation practices. In Hallin and Mancini's (2004, pp. 41-44) comparative media systems analysis the other dimension is (4) extent of the state intervention in the media system in such a country. This dimension refers to the role of the state in shaping the structure and functioning of media systems. The researchers established five indicators to assess the extent of the state's intervention on media. These indicators are: Censorship or other types of political pressure, ownership patterns of the media, and telecommunication organizations. The other indicator of this dimension consists in the provision of regulations for the media and endowment of the media with economic subsidies. Moreover, the final indicator is the state as an information source and primary definers of news. With the advent of the new information and communication technologies, these possibilities are being discussed in the national public sphere in Turkey. The distribution of Turkey's internet users by technological infrastructure is shown in Table 6 .

As shown in Table 6, the number of internet users rises continuously, but this increase is not followed by the new media sector, particularly by internet service providers. As seen in Table 7, Turkey's internet service providers show a high degree of ownership concentration in the market, even demonstrating intensified monopolization trends. Thus, one company (TTNET) almost fully dominates the market. 
Table 6. Percentage of the Distribution of Internet Users in Turkey

\begin{tabular}{|c|c|c|c|c|c|}
\hline $\begin{array}{l}\text { Technological } \\
\text { Infrastructure }\end{array}$ & 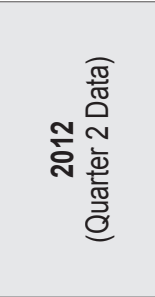 & ๗ & 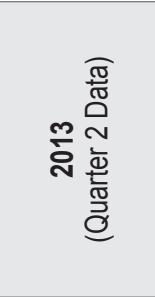 & 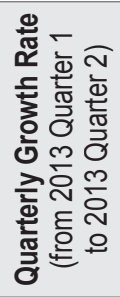 & 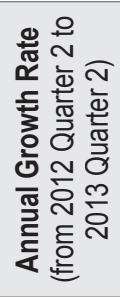 \\
\hline Xdsl & $6,632,661$ & $6,678,907$ & $6,644,571$ & -0.5 & 0.2 \\
\hline $\begin{array}{l}\text { Mobile Internet } \\
\text { from Computer }\end{array}$ & $1,582,984$ & $1,727,861$ & $1,746,814$ & 1.1 & 10.3 \\
\hline $\begin{array}{l}\text { Mobile Internet } \\
\text { from Mobile Handset }\end{array}$ & $15,908,739$ & $19,041,609$ & $20,038,053$ & 5.2 & 26.0 \\
\hline Cable Internet & 485,531 & 501,201 & 491,582 & -1.9 & 1.3 \\
\hline Fiber Internet & 499,668 & 741,665 & 880,871 & 16.1 & 88.3 \\
\hline Other & 140,299 & 137,366 & 126,884 & -7.7 & -9.6 \\
\hline Total & $25,219,882$ & $28,826,669$ & $29,908,985$ & 3.7 & 18.6 \\
\hline
\end{tabular}

Source: www.icta.gov.tr: 2016, p.30.

Table 7. Internet service providers and their market share in Turkey

\begin{tabular}{lc}
\hline Internet Service Provider Name & Market Share (\%) \\
\hline TTNET & 80.62 \\
Superonline & 10.14 \\
Dogan Television Digital & 4.49 \\
Milenicom & 1.51 \\
Vodafone Net & 1.48 \\
Turk Net & 0.96 \\
Metronet & 0.47 \\
İş Net & 0.06 \\
Eser & 0.05 \\
Him Net & 0.04 \\
Other & 0.18 \\
\hline
\end{tabular}

Source: www.icta.gov.tr, 2016 p. 29.

As noted above, another restriction stems from the traditional news media that migrated into the new media environment. A large portion of online journalism originates in traditional news media, whether the aspects migrated into the new media world or arisen as digital natives. Some writers like Lipinski and Neddenriep interpreted this fusion as a new method for seeking coverage from old media. As Lipinski and Neddenriep (2004, p. 7) state,

"the internet is often viewed as a replacement of the old modes of communication, a tool used by new seekers, including public officials, to bypass traditional news media. However, the authors show that the arrival of this new media has not caused officials 
to forsake journalist and abandon traditional media. Instead, they are utilizing the Web as a new method for seeking coverage from the old media."

In terms of online journalism, the main question stems from media revenues. However, Grabowicz (2014, p. 1) assumes that "financial viability for newspapers and most of the magazines, at least for now, requires retaining as many existing print readers as possible. Yet the trends are clear: People, especially young, are turning to the internet for more and more of their news and developing an effective digital strategy is essential for long-term survival." However, social media and news media signify different aspects of the new media ecology, and this news reading style is gradually converged into the new media world. Recently (the research was conducted using data from the second quarter of 2013), the internet and social media in particular have increased popularity by $40 \%$, and this comprises two-thirds of the total news reading rates.

However, even if new media became the dominant tools for news reading, an important problem emerges from the so-called old media ecology. Although online journalism outlets stand as a new way to access the news, the problem revenue, particularly the share of advertisement revenue in traditional news media remains. Table 8 illustrates Turkey's advertisement revenues and sharing trends among media outlets.

Table 8. Internet advertisement revenues in Turkey

\begin{tabular}{|c|c|}
\hline Classified Internet & Revenue (million dollars) \\
\hline Display Advertisement Budget & 169.10 \\
\hline Viewing or Clicking & 131.87 \\
\hline Video on Demand & 15.69 \\
\hline Generated by the Sponsors & 13.05 \\
\hline Revenue Sharing Advertisement & 8.49 \\
\hline Web Search Advertisement & 196.53 \\
\hline Word Based Advertisement & 135.57 \\
\hline Viewing Based Advertisement & 60.96 \\
\hline Mobile Advertisement & 14.94 \\
\hline Mobile Video Advertisement & 4.45 \\
\hline Mobile SMS or MMS Advertisement & 10.49 \\
\hline Online Advertisement Page & 32.74 \\
\hline Other & 3.46 \\
\hline E-Mail Advertisement & 1.93 \\
\hline In-Game Advertisement & 1.53 \\
\hline Total Internet Advertisement Budget in Turkey (2012) & 416.77 \\
\hline
\end{tabular}

Source: www.iab.org.tr, 2016, p.34.

Having newly established and developed marketing techniques in Turkey, internet marketing and advertisement are of vital importance for online journal- 
ists and journalistic outlets. But online journalism must share this revenue with traditional mass media in Turkey, because traditional mass media outlets have migrated into the new media realm gradually, and due to the close relationship between traditional media conglomerates and online journalistic outlets. Additionally, whether migrated into the new media realm world/ecology or born in the digital media world, mass media share revenues just as they do all over the Western world. However, new media have led to new opportunities for advertisement revenue generation based on the nature of the new world (interactivity, synchronization and so on). Therefore, the new media ecology offers potential for both traditional and digital-born outlets. But the most important questions still remain unanswered. These questions, initially simple, are of vital importance for current and future generations of online journalists. How do journalists in Turkey discuss the emergence of these specific technological forms? When are new forms seen as contributing to the practices of journalism and when as threatening it?

\section{Methods and the Case Study}

To address the aforementioned research questions, the author attempts to distinguish online and traditional journalism's roles in terms of their continuity and discontinuity in the field of journalism. Although there are upward of 30 million internet users (www.internetworldstats, 2016, p. 2) and great opportunities for creation of new content and journalistic style, it seems that traditional journalism and journalistic routines have remained unchanged even within the online media ecosystem. To understand the online media ecosystem in Turkey, a general overview and analysis of Turkey's internet infrastructure such as user potential and usage practices is vital. In the research, I analyzed these ongoing inequalities in the heart of information society. In addition to analyzing digital divides, I carried a research based on two different methodologies. On one hand, Likert attitude analysis was employed in carrying out this study, and this survey is conducted on traditional and online journalists encompassed in the study $(\mathrm{N}=126)$. As noted above, during the survey and deep interviews, the research have deal especially with two topics. These are (1) from traditional to new media driven journalism in Turkey, continuity and discontinuity aspects of the journalism and (2) journalists' changing perceptions of occupation from traditional to new media ecology. In this sense, the research questions are: How do journalists in Turkey discuss the emergence of these specific technological forms? When are new forms seen as contributing to the practices of journalism and when as threatening it?

On the other hand, the study analyzed online journalists' perception on online journalism as a profession, through in-depth interviews $(\mathrm{N}=22)$. In this sense, the selection criteria of the journalist are mainly based on two criteria. One would be journalists' working conditions, such as traditional outlets or new media ecol- 
ogy, and journalists' status in the news station. The other criterion would be journalists' age, sex, education, and journalist income, as complementary aspects of the selection criteria. However, in-depth interviews are conducted only with new media journalists. Moreover, the other 74 respondents come from internet-based news outlets. As for other selection criteria, all of the respondents have Bachelor's degrees from national universities under varied departments and, during the research, 12 online journalists were still M.A. or Ph.D. students in Turkey. Five journalists were attendant journalists in training fellowship programs, especially England and Germany's Journalist's Foundations. Gender is also an important aspect in selecting respondents; the author included 42 female journalists in the study.

Likert attitude analysis is very useful for the purposes of this research, because this technique, based in social sciences, employs open-ended questions, and ensures active participation from both the researcher and the respondents. Like all attitude scales, Likert attitude analysis assumes that attitude strength/intensity is linear, ranging on a continuum from "strongly agree" to "strongly disagree," making it possible to measure attitudes (Camparo and Camparo, 2013, p. 82).

In the study, the Likert attitude scale is used complementary to the in-depth interviews, to gather information on journalists' self-reflexivity and perceptions of online journalism. Interviews were conducted with 22 young journalists (ranging from 25 to 35 years of age) working as correspondents in national media groups in Turkey. They are all engaged in content creation and constant use of social media. Therefore, these journalists are used to the "immediate" and "unfiltered" nature of social media (Sivek 2010, p. 157). Since they are more familiar with social media and new communication technologies, they are assumed to expect interactions between journalists and new media in both their personal lives and professional carriers. Nikki Usher (2010, p. 913) interprets this interaction as a "goodbye for journalism." Whatever the interpretation for journalism or the brink of a new era for journalists, a transition for journalists and journalistic routines based on new media mediation is apparent. During the interviews, participants were asked to discuss the general conditions of Turkey's media landscape, particularly unemployment in the sector, the future of journalism, general problems faced by the field, their perceptions of journalism, and their self-reflective practices as journalists. The aim of the interviews was to provide insight on journalism in Turkey in general, and on the attitudes, opinions, and behaviors of journalists, and the interactions between journalists and new media in particular.

The in-depth interviews and the survey based on Likert attitude analysis were very useful not only in providing a method for systematic knowledge gathering on journalists/new media interactions, but also for conducting deep and meaningful interpretation of this interaction and its future development. Journalist and new media interactions must thus be conceptualized within the media system. 
Hence, the principles and practices of universal service that incorporate openness and accountability, ethics, democratic communication, freedom of expression in the market, and diversity of both content and ownership are important factors determining media systems. They provide meaningful inquiry into the future of journalism such as news production and journalistic routines, by contrast to traditional journalism. For news production and journalistic routines, new media were seen as more of a threat than an opportunity in terms of these assessments. Compared with traditional journalism, new media and its news production provide important tools for the news media, and the internet also provides convenient access to a wider range of international news outlets (Chan, Lee and Pan 2006; p. 926). However, an analysis of the macro structures of journalism, such as ownership of media outlets, the digital divide, and penetration rates, reveals ethical and otherwise unintended problems facing journalism. Thus, we must acknowledge enduring problems in the new media world.

\section{Becoming an Online Journalist in the Concentrated Media World}

Mark Deuze (2003, p. 207) states that the new digital interactive media climate has also provoked a shift of the definition of news from a focus on editorial content to connectivity with the audience. The blurring boundaries between journalist and citizen and their practices arise from citizens' involvement in the news-making process and a new form of journalism (civic journalism) has ultimately emerged, based on the internet's technological facilities in the new era of journalism and journalistic practices. However, as Nah and Chung (2012, pp. 726-727) state, internet's facilities create these blurred boundaries between professional and citizen journalism. In addition, as Nah and Chung (2012, pp. 726-727) have mentioned, "online news sites can function as an open terrain to the possibilities and potential of whether professional and citizen journalists can contribute to the public sphere necessary for health democracy. That is, while both types of journalists compete and contribute for news production and consumption, citizen journalists can supplement the roles of professional journalists (e.g. Gillmor 2009) or function as sources of non-traditional and alternative journalism (e.g. Deuze, 2009, Kenix 2009, Lowery 2009) sharing editorial journalistic roles and even creating newly emerging roles."

Therefore, these emerging citizen journalists' roles vis-à-vis the traditional roles of professional journalists can influence media credibility and perceived conceptions of roles by news audience and vice versa. In this sense, as Agarwal and Barthel (2015, p. 378) have pointed out, "research into journalistic role perceptions has identified four primary media functions: disseminator, interpreter, adversarial and populist mobilizer." In each role, perceptions have addressed different functions of the media and journalist interaction. However, these journalistic roles are not constant and stable. As in Agarwal and Barthel's assessment (2015, p. 378), 
"the defining characteristic of these roles is whether the journalist adopts a neutral or participatory approach to reporting."

With the advent of the internet and the new media ecology based on the internet and other related technologies, new journalism practices are developed, but this new development sometimes paves the way of unintended consequences particularly for professional journalists who contemplate journalism as a career. For example, the Turkish journalists in this research, particularly those working for mainstream television channels and newspapers, think of citizen journalism as undermining media credibility. In this respect, Nah and Chung's study is a call to rethinking media credibility. They determined (2012, p. 714) that "while media credibility was positively related to the role conceptions of professional journalist only, social trust was positively associated with the role conceptions of both professional and citizen journalists." In the study, Nah and Chung's determination is especially applicable to Turkey's mainstream television channel and newspaper employees.

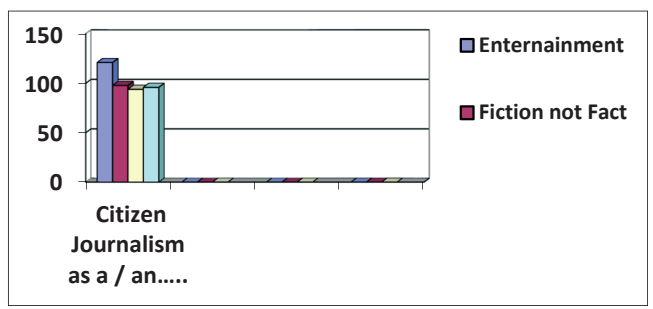

Figure 1. How professional journalists in Turkey perceive citizen journalism ( $N: 126)$.

Figure 1 shows the prejudice of professional journalists against citizen journalism, even if this new form encourages healthy democracy. But the reaction is unsurprising, at least for communication researchers such as Fröhlich, Quring and Engesser (2012, p. 1041). These researchers conducted studies in Germany on participatory journalism, with respect to traditional journalism practices, and concluded (2012, p. 1055) that their respondents prefer entertainment journalism, even though "one has to consider comparison with professional online and offline journalists." This statement underlines the transformation to a meaningful judgment, especially when new media and new media-driven journalism have been the subject of critical analysis. Given the close relationship between virtual and real public sphere, the way for the media's new function as plurality, given the real conditions of online journalism, show it as far from this statement. Therefore, online journalism is weak and does not have the potential to foster meaningful democracy. Nonetheless, according to traditional journalism, online journalism and online journalists take for granted the independent and libertarian voices of the public sphere. As Weiss and Joyce $(2009$, p. 526) state, "technology is not the 
sole determinant of these transformations. The cultural and social implications of the new technology are as much influencing forces as they are influenced by it." For instance, a Turkish online journalist pointed out that online journalism and new technology attempt to accomplish two related things. First, they seek active participation from the audience in the process of news construction, second, new technology brings the audience real information, and by multimedia, converting the online sites into a type of town square, a place where the community gets together. These two processes occur with little or no interference from the journalists. As another online journalist points out, "the new technology is providing to the audience to being active participants in the communication process." Therefore, advocates of online journalism have identified the journalist's role as enlisting audience participation by providing platforms for audience expression and citizen connectivity. For instance, Kopper (quoted in Weiss and Joyce 2009, p. 527) states that the interactive aspect of the internet allows people to participate in public discourse, with beneficial consequences to democracy. With respect to public sphere theory, Habermas (1991, p. 128) states that the participation of citizens in debates where political decision and consensus are formed would be essential for democracy, working to restrain authoritative power. In this respect, the new media ecology by mediation of the internet can provide a venue for interactive aspects of the public sphere. Having offered citizens a platform and important tools for exchanging opinion and information, online journalism also provides citizens with the information needed to make political decisions, offering a dual purpose in the maintenance of democracy.

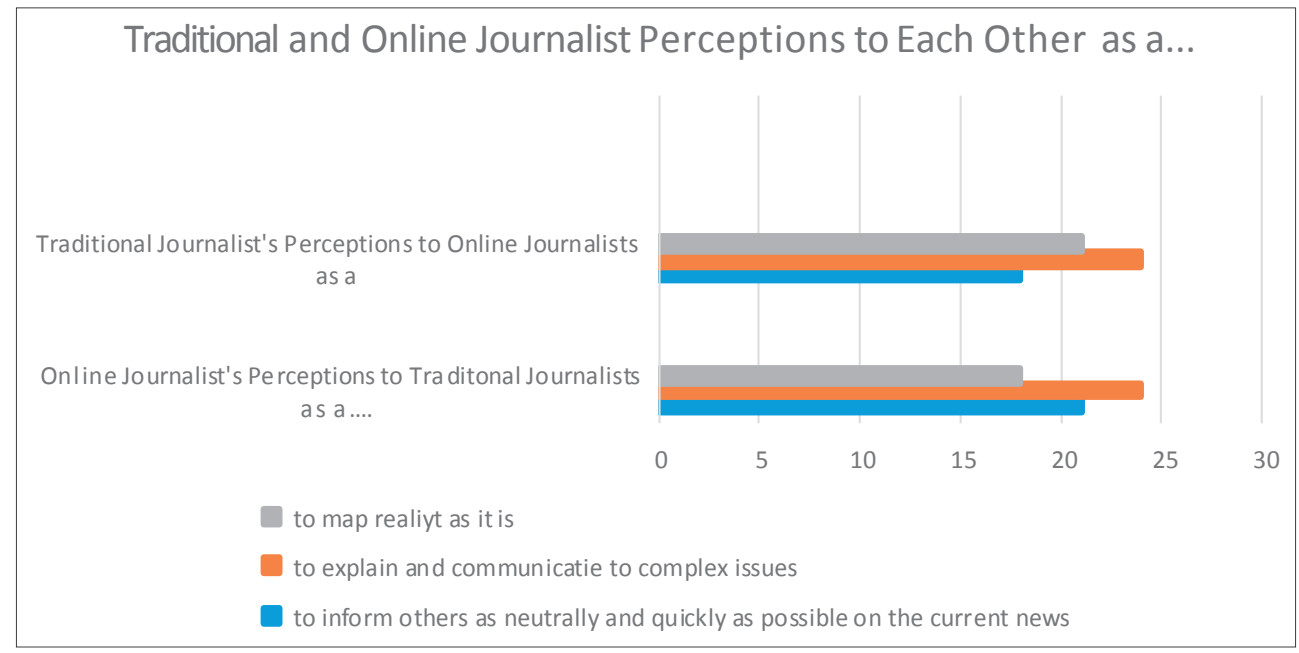

Figure 2. How the role of online journalist as moderators and synthesizers of public debate is perceived by traditional journalists ( $\mathrm{N}: 126)$ 
Figure 2 is based on the field research of this study and reflects both traditional and online journalists' perceptions of each other. The bars in Figure 4 reflect three variables: the blue bar indicates the levels of "independency perception" - which is labeled "to inform others as neutrally and quickly as possible on the current news sources;" the red bar indicates the levels of "communicate or explanative perception," and grey bar indicates the level of objectivity, coded as a "to map reality as it is." Yet, within this study, online and traditional journalists' perceptions are based on "competition" and "threat to each other." Therefore, the media market situation in Turkey is far away from the dominant paradigms in communication studies. For instance, many studies show that online journalism in traditional media institutions tends to retain gatekeeping control over news-making, despite opening up somewhat to the audience for re-evaluation of the online journalist's role in news-making; for detailed discussion on this topic, see Vobic and Milojevic (2013, pp. 5-8). However, in the course of this study, almost all bars show steady decline, especially the online journalist's perception, that is more pessimistic than traditional journalist's perception. During the study, online journalists perceived themselves as disseminators of the news, while traditional journalists perceived themselves as an objective and neutral source of the news. Vobic and Milojevic (2013, p. 5) noted that online journalists may feel inadequate because their newsmaking rests primarily on already published information and interpretation of information available online, downsizing their relevance in political life to "second hand" journalists. In Turkey, this is especially true. Unlike their traditional colleagues, Turkish online journalists find themselves at a disadvantage in gathering, assembling, and producing news items throughout their work shifts, to respond to the assumed needs of, as described by Rosen (2012, p. 14), "people formerly known as the audience." In light of this problem, online journalists in some cases cope with the demand for immediacy and continuous news by seldom providing original content. Instead, they "copy-paste" content from agencies or "monitor" other media, and "mimic" their news. As Vobic and Milojevic (2013, p. 5) explain, due to constant time constraints, online journalists hardly ever leave their desk and newsrooms, developing a sense of inferiority to imagined "true" journalists reflected by phrases such as "mouse monkeys" or more politely "desktop journalism." In general, however, online journalistic routines predominantly belong to the same group, creating a new culture and generating specific values in the newsroom, based on convergence in the news-making process. For instance, Deuze $(2009$, p. 85) points out that the "demise of the reporter" leads to the rise of "new kind of workers" with less social production and fewer labor rights, who can be more accurately labeled news producers than journalists. In contrast to online media institutions, research on traditional media institutions identified an ever greater division between "privileged professionals" who enjoy greater job 
security and career development in print or broadcast media and a "periphery of semi-affiliated professionals" in subcontracted arrangements, often working in online departments.

Moreover, there are some similarities and differences in the online journalism experiences of Turkey and the European Union. Bayraktar's (2011, pp. 6-7) study explains these similarities and differences as follows. Turkey and European Union's new media journalisms shared both of principles of alternative online broadcasting are stated clearly global perspectives and hate crimes and income sources and financial stability are threatened by inability to pay cost in existing forms of online publication. Besides financial problems Turkey and European Union's new media journalism also lack of accuracy in controlling feedbacks. Although some similarities are visible in Turkey and European Union's new media journalism, there are also has got main differences. Among the ongoing differences, perhaps the lack of strong institutional system of check and balance is the most important for new media journalism routines. Hence, the absence of check and balance systems are paved the way for the Turkey's new media journalism is plagued by corruptions such as prevalence of fake news and the loose of credits to new media journalism. In addition to the gradually loose of confidence another problem is lack of established culture of new media journalism in Turkey. Moreover, new media journalism in Turkey have affected adversely the lack of legal status. As a result of the lack of legal status and policy framework, the legal status of new media journalist's in Turkey is deeply have got some peculiarities, especially whether they are "journalist" or not. Commenting on the institutional status and self-deprecation of online journalists, Garcia (2008, p. 73, quoted in Vobic and Milojevic 2013, p. 6) notes that they regard themselves as "half stupid" and "minor brothers" of print journalists. In contrast, as Russell (2011, p. 2) state, "networked journalism is about more than journalists using a digitally equipped public as a kind of new hyper/source. It is also about a shift in the balance of power between news providers and news consumers." Therefore, the main differences between online and traditional journalists are not only their use of digital devices at certain levels, but also more and more importantly, their establishment of a new culture and new media ecology. Thus, online journalism is a strong voice for a future better than today's.

\section{Discussion and Conclusion}

During the time of this research, the most striking difference found between traditional and online (or new media-driven) journalists was the self-concept or self-reflection in the journalistic role and function. The group of online journalists in this research regard themselves to a lesser extent as neutral mediators, which are important indicators for journalistic professionalism. Moreover, the most important subjective criteria for topic selection, beyond personal interest or concern, are seen as more important than journalistic criteria like relevance or actuality. 
In this respect, perhaps surprisingly, the in-depth interviews in this study underlines few substantial differences between professionalism and journalistic culture. Therefore, news values and news criteria are nearly the same for journalists, regardless of where they work. This close relationship may only apply among the respondents to this research. Moreover, creativity, ideas, and fun seem to be the most important motivations for taking part in both media formats, though online journalists are fondest of these elements. The most important difference is the journalists' intention to actively take part in public communication.

This research revealed that traditional journalists are more motivated to intervene in the public sphere's agenda, particularly the political agenda, than online journalists. However, they often fail to satisfy their needs. The driving motivation of the journalists, such as to become famous or to act as a pioneer in public affairs, seems more common among online journalists. But differences play only a minor role: the respondents of the study seem to see their engagement not as a stepping stone in a journalistic career, but rather as a way to fill niches that traditional journalism does not or cannot serve ideally. In addition, this study also identified similarities between online and traditional/professional journalists. An examination of the qualifications and expertise of the study's respondents (N: 126) shows that journalistic experience is common among them, as one third already have experience in traditional journalism, $8 \%$ work as full-time journalists, and $11 \%$ work in the broader media field, such as production team worker or freelance journalist. Furthermore, the majority of respondents may identify with a typical description of journalistic tasks of "gathering information, selecting and publishing the most important information and only additionally giving one's own interpretation and opinion." However, Hartley's (2000, p. 42) assumption that everybody on the internet is a potential journalist ("everyone is a journalist") and the notion that we are headed toward an "editorial staff society" (Neuberger, 2004, p. 2 quoted in Fröhlich, Quirring and Engesser 2012, p. 1060) were considered a bit too extreme.

The result of this study suggests it is a slight exaggeration to reduce journalism to the pure process of publishing and to ignore traditional journalism's specific benefits and skills of gathering, mediating, and interpreting news. Indeed, online journalism is seen as very promising for new media and democratic communication possibilities. Though online journalism may complement or enliven traditional journalism, it cannot fully replace its benefits. Online journalism fills niches that traditional media cannot fill because of market pressure, ownership concentration, and profitability issues. In this regard, this study suggests that online journalism contributes to a diversity of opinions and topics, and can offer important stimulation to traditional journalism regarding authenticity, equality, and audience orientation. In cases of catastrophe, natural disaster or tragic accidents, citizens are often on site before professional journalists. Integration and collaboration with the audience increase trust and reader loyalty toward traditional mainstream 
media, especially in times of audience emancipation. Collecting reader feedback and important information about the needs, preferences, and expectations of the audience is also important in creating more market-oriented media products, especially in the face of economic threats. Traditional journalists must realize that readers will grow more interested in participating in and evaluating media. At least in certain areas, traditional journalists will find themselves more and more in a mediating role, managing content produced by participatory journalists. The increasing importance of online journalism should therefore not be seen as a risk, but as an opportunity for traditional media. Hence; the new media journalism as an emerging journalism branch, represents a new era of journalism at least two interrelated and important aspects. On one hand, as a gradually growing field of journalism especially in Turkey, new media journalism is a means for acceleration for the changing boundaries of news reporting. During the research of this article, respondents have frequently to stress of these dimension of the changing nature of journalism. For respondents of this article, new media journalism has effectively transformed the nature of the news culture in Turkey. Although Turkey's national media landscape and national journalism culture have severally plagued by rising press/party parallelism, the pressure of media ownerships and in this sense only a few media conglomerates hegemony on the national media sectors and the weakening editorial autonomies some positive developments are emerging such as new media journalism, online news outlets and in this sense the new journalism cultures. In this study, the author of this article has evaluated some dimensions of the new media journalism and new media ecology by the means of Turkey's new media journalism case. In this sense, to some extent, new media journalism and its culture is seen as a new pluralistic channels in the public sphere especially in the absence of free, fair and well-established, accountable, media outlets and journalistic culture. To say that new media journalism's culture and newly established online news outlets consist of pluralist and participatory mediums than the traditional mass media. However, this hopeful scene is required to accountable, respectful and ethical journalism and journalism culture. In this conditions the new media journalism is becoming an initial step for powerful democracy.

\section{References}

1. Agarwall, D. S., and Barthel L. M. (2015). The Friendly Barbarians: Professional Norms and Work Routines of Online Journalist in the United States. Journalism, 16(3), 376-391.

2. Akgül, Elif (2016). "Media Ownership Monitor Project: Who Owns the Media in Turkey". Retrieved from https://m.bianet.org/bianet/diger/180063-who-owns-themedia-in-turkey. Accessed on 25 October 2017.

3. Alejandro, J. (2010). Journalism in the Age of Social Media. Oxford: Reuters Institute for the Study of Journalism. 
4. Bayrakdar, D. (2011). Upheaval in Turkish Media. Retrieved from http://is.jrc. ec.europa.eu/pages/ISG/MCI/documents/BayrakdarDeniz.pdf. Accessed on 8 December 2014.

5. Camparo, J., and Camparo, B. L. (2013). The Analysis of Likert Scales Using States Multipoles: An Application of Quantum Methods to Behavioural Sciences Data. Journal of Educational and Behavioural Statistics, 38(1), 81-101.

6. Çarkoğlu, A. and Yavuz, G. (2010). Press-Party Parallelism in Turkey: An Individual Level Interpretation. Turkish Studies, 11(4), 613-624.

7. Chan, M. J., Lee, L. F., and Pan, Z. (2006). Online News Meets Established Journalism: How China's Journalists Evaluate the Credibility of the News Websites. New Media and Society, 8(6), 925-947.

8. Ciaglia, A. (2013). Politics in the Media and the Media in Politics: A Comparative Study of the Relationship Between the Media and Political Systems in Three European Countries. European Journal of Communication, 28(5), 541-555.

9. Deuze, M. (1999). Journalism and the Web: An Analysis of Skills and Standards in an Online Environment. International Communication Gazette, 61(5), 373-390.

10. Deuze, M. (2003). The Web and its Journalism: Considering the Consequences of Different Types of News Media Online. New Media and Society, 5(2), 203-230.

11. Deuze, M. (2007). Media Work. Cambridge: Polity Press.

12. Deuze, M. (2009). Beyond Journalism. Cambridge: Polity Press.

13. Freedom House (2016). Turkey Report, www.freedomhouse.org (2016). Retrieved from https://freedomhouse.org/reports. Accessed on 8 December 2016.

14. Frohlich, R., Quiring, O., and Engerster, S. (2012). Between Idiosyncratic Self-interest and Professional Standards: A Contribution to the Understanding of Participatory Journalism in Web 2.0. Results from an Online Survey in Germany. Journalism, 13(8), 1041-1063.

15. Doyle, G. (2016). Creative Economy and Policy. European Journal of Communication, Vol. 31(1), 33-45.

16. Grabowicz, P. (2014). The Transition to Digital Journalism. Retrieved from www. multimedia.journalism.berkeley.edu. Accessed on 8 December 2014.

17. Habermas, J. (1991). The Structural Transformations of the Public Sphere: An Inquiry into a Category of Bourgeois Society. Translated by Thomas Burger with the assistance of Frederic Lawrance. New York: MIT Publication.

18. Hallin, C. D., and Mancini, P. (2004). Comparing Media Systems: Three Models of Media and Politics. Cambridge, MA: University Press.

19. Hartley, J. (2000). Communication Democracy in a Redaction Society: The Future of Journalism Studies. Journalism, 1(1), 39-48.

20. Heinrich, A. (2012). What is Network Journalism. Media International Australia, 144(1), 60-67.

21. Information and Communication Technology Authority. (2016), Electronic Communication Market in Turkey. Retrieved from www.btk.gov.tr/File/?path=ROOT 
\%2F1\%2FDocuments\%2FPages\%2FMarket_Data\%2F2016-Q2-En.pdf. Accessed on 25 October 2017.

22. Internet World Stats (2017). Internet World Growths Between the Years 2012 to March 2017. Retrieved from www.internetworldstats.com/emarketing.htm. Accessed on 27 March 2017.

23. Internet World Stats (2017). Turkey Internet Users Retrieved from www.internet worldstats.com/me/tr.htm. Accessed on 27 March 2017.

24. Internet World Stats (2017). “Top 20 Internet Countries with the Highest Number of Internet Users in 2017". Retrieved from www.internetworldstats.com/top20.htm. Accessed on 27 March 2017.

25. Internet World Stats (2014). Internet and Facebook Usage in Europe. Retrieved from www.internetworldstats.com. Accessed on 27 March 2017.

26. Internet World Stats (2014). Top 10 Internet Countries in Europe. Retrieved from www.internetworldstats.com. Accessed on 27 March 2017.

27. Kaya, R., and Çakmur, B. (2010). Politics and the Mass Media in Turkey. Turkish Studies, 11(4), 521-537.

28. Lippinski, D., and Nedderiep, G (2004). Using New Media to Get Old Media Coverage: How Members of Congress Utilize Their Web Sites to Court Journalists. PressEP Politics. 9(1), 7-21.

29. Nah, S., and Chung, D. S. (2012). When Citizens Meet Both Professional and Citizen Journalists: Social Trust, Media Credibility, and Perceived Journalistic Roles Among Online Community News Readers. Journalism, 13(6), 714-730.

30. Rosen J. (2012). People formerly known as the audience. In Mandiberg, M. (ed.), The Social Media Reader (13-16). New York: NYU Press.

31. Rosen, J. (2012). "People Formerly Known as the Audience", Retrieved from www. huffpost.com. Accessed on January 2017.

32. Russell, A. (2011). Networked: A Contemporary History of News in Transition. London and New York: Polity Press.

33. Sivek, S. C. (2010). Social Media under Social Control: Regulating Social Media and the Future of Socialization. Electronic News, 4(3), 146-163.

34. Usher, N. (2010). Goodbye to the News: How Out of Work Journalist Assess Enduring News Values and the New Media Landscape. New Media Society, 12(6), 911-928.

35. Vobic, I, and Milojevic, A. (2013). What we do is not Actually Journalism: Role Negotiations in Online Departments of Two Newspapers and Slovenia and Serbia. Journalism. XX $(\mathrm{X}), 1-18$.

36. Weiss, A. S. (2014). The Digital and Social Media Journalist: A Comparative Analysis of Journalists in Argentina, Brazil, Colombia, Mexico and Peru. The International Communication Gazette, 77(1), 74-101.

37. Weiss, A. S., and Joyce, V. M. (2009). Compressed Dimensions in the Digital Media Occupations: Journalist in Transformation. Journalism, 10(5), 587-603. 